Verhaak, P., Zee, D. van der, Conradi, M., Bos, R. Praktijkondersteuner-ggz maakt verwachtingen waar. Tijdschrift voor Praktijkondersteuning: 2012, 7(2), 41-46

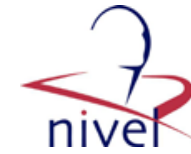

\begin{tabular}{|l|l|}
\hline Postprint Version & 1.0 \\
\hline Journal website & http://www.tijdschriftpraktijkondersteuning.nl/archief/id633-praktijkondersteuner- \\
\hline Pubmed link & ggz-maakt-verwachtingen-waar.html \\
\hline DOI & \\
\hline
\end{tabular}

This is a NIVEL certified Post Print, more info at http://www.nivel.eu

\title{
Praktijkondersteuner-ggz maakt verwachtingen
}

\section{waar.}

\section{Peter VerhaAK, Douwinde VAN DER ZeE, Marc ConRadi En RoELinda Bos.}

Nivel, Postbus 1568, 3500 BN Utrecht en UMCG, Groningen: prof.dr. P.F.M. Verhaak, programmaleider GGZ en eerste lijn (Nivel) en hoogleraar GGZ in huisartspraktijk. UMCG Groningen: D.A.A.Y. van der Zee, student geneeskunde.

ELANN (Eerste Lijns Advies Noord-Nederland): dr. M. Conradi, extern adviseur en R. Bos, adviseur eerstelijnszorg.

Correspondentie: P.verhaak@nivel.nl.

Mogelijke belangenverstrengeling: geen.

Het onderzoek is opgezet als een wetenschappelijke stage waarvoor Douwinde van der Zee de dataverzameling heeft verricht. Peter Verhaak heeft een en ander opgezet en begeleid uit hoofde van zijn functie aan de vakgroep Huisartsgeneeskunde.

De portokosten en kopieerkosten voor vragenlijsten en formulieren zijn betaald door ELANN.

\section{SAMENVATTING}

Doel De praktijkondersteuner geestelijke gezondheidszorg is een relatief nieuw fenomeen in Nederland. Er is niet veel bekend over de dagelijkse werkzaamheden en over de variatie in werkzaamheden tussen de praktijkondersteuners- ggz. Dit is het eerste onderzoek naar de werkzaamheden van praktijkondersteuners-ggz.

Methode Gedurende drie maanden registreerden negentien praktijkondersteuners-ggz hun activiteiten per patiënt. De patiënten vulden een korte vragenlijst in. De praktijkondersteuners-ggz registreerden de symptomen van de patiënten, de behandeling, de eventuele verwijzing, en de duur van de sessie.

Resultaten Praktijkondersteuners-ggz komen de meest gangbare psychische en psychosociale problemen tegen.

Ze hebben gemiddeld ongeveer drie contacten, en zelden meer dan vijf per patiënt. Ongeveer tweederde van de patiënten krijgt enige vorm van behandeling en bij eenderde volgt een verwijzing, meestal naar een eerstelijnspsycholoog of specialistische ggz.

Beschouwing Uit deze eerste resultaten concluderen wij dat een praktijkondersteuner-ggz een belangrijke aanvulling kan bieden op de huidige geestelijke gezondheidszorg, in het bijzonder bij probleemverheldering en bij doorverwijzing naar de juiste instantie. 
Verhaak, P., Zee, D. van der, Conradi, M., Bos, R. Praktijkondersteuner-ggz maakt verwachtingen waar. Tijdschrift voor Praktijkondersteuning: 2012, 7(2), 41-46

\section{INLEIDING}

Het is ongeveer vier jaar geleden dat de praktijkondersteuner geestelijke gezondheidszorg (praktijkondersteuner-ggz) in de huisartsenpraktijk werd geïntroduceerd, als voortzetting op de ondersteuning door de sociaalpsychiatrisch verpleegkundigen. De praktijkondersteuner-ggz is geen gesubsidieerde voorziening: de zorgverzekering vergoedt deze zorg via een mix van abonnement en verrichtingen in principe aan de huisartsvoorziening waarbij de praktijkondersteuner- ggz in dienst is. Dit in tegenstelling tot indertijd de sociaalpsychiatrisch verpleegkundige, die in de zogeheten consultatieregeling viel.

Van de praktijkondersteuner-ggz werd verwacht dat deze minder vanuit een uitsluitend 'psychiatrisch' perspectief zou werken dan de sociaalpsychiatrisch verpleegkundige, die vanuit de ggz in de eerste lijn ging werken. De praktijkondersteuner-ggz zou vanuit een generalistische hulpverleningsvisie gaan werken.

Dit betekent dat een praktijkondersteuner-ggz aan de hand van onduidelijke symptomen door probleemverheldering moet bepalen of er sprake is van een sociaal probleem, een tijdelijke inzinking die vanzelf overgaat, of een psychische stoornis die nadere aandacht behoeft. De praktijkondersteuner-ggz zou minder nadruk op kortdurende behandeling moeten leggen dan de sociaalpsychiatrisch verpleegkundigen deden. De primaire taak van de praktijkondersteuner- ggz zou namelijk zijn om de patiënt met psychische problemen te geleiden naar de juiste setting voor behandeling, zonder dat de praktijkondersteuner- ggz zelf die behandeltaken op zich zou nemen.

\section{Probleemverheldering}

Probleemverheldering, signalering en eventuele nadere diagnostiek zijn daarom belangrijke taken voor de praktijkondersteuner-ggz. Op basis daarvan kan hij een advies aan de huisarts geven, of kan de praktijkondersteuner-ggz eventueel zelf kortdurende interventies uitvoeren die niet meer dan enige contacten in beslag zouden moeten nemen. Behandeling moet geen hoofdtaak worden: daarvoor kan de praktijkondersteuner-ggz, op basis van zijn bevindingen, de patiënt doorgeleiden naar de plaats waar deze het beste verder geholpen kan worden. Dit kan in de eerste lijn bijvoorbeeld het algemeen maatschappelijk werk zijn of een eerstelijnspsycholoog. Bij vermoeden van een ernstige psychische stoornis zal de praktijkondersteuner-ggz in overleg met de huisarts verwijzen naar een ggzinstelling. Deze taakomschrijving is ontleend aan visiedocumenten over de functie praktijkondersteuner-ggz. ${ }^{1,2}$ Hoe de functie in de praktijk gestalte krijgt, weten we tot op heden alleen via een enquête onder praktijkondersteuners- ggz. Hierin gaven 75 praktijkondersteuners- ggz die begin 2010 werkzaam waren, globale schattingen van hun eigen functioneren. ${ }^{3}$ Probleemverheldering, signalering en kortdurende behandeling noemden zij als meest voorkomende activiteiten. Echte registratie van de werkzaamheden van de praktijkondersteuner-ggz had nog niet plaatsgevonden. Dergelijke gegevens zijn gewenst om de volgende redenen. De functie praktijkondersteunerggz is tamelijk ruim omschreven. Inzicht in de wijze waarop praktijkondersteuners-ggz daaraan in verschillende situaties gestalte geven, levert leermomenten op voor anderen en kan bijdragen aan een nadere definitie van de functie praktijkondersteuner-ggz. Dit is onder meer van belang voor de opleidingen die thans nog op verschillende manieren invulling geven aan een curriculum voor de praktijkondersteunerggz. 
Verhaak, P., Zee, D. van der, Conradi, M., Bos, R. Praktijkondersteuner-ggz maakt

verwachtingen waar. Tijdschrift voor Praktijkondersteuning: 2012, 7(2), 41-46

De gegevens zijn ook nuttig voor huisartsen die overwegen om een praktijkondersteuner-ggz in dienst te nemen. Ten slotte zijn de gegevens interessant voor de overheid, die een toekomstige eerstelijns-ggz gestalte wil geven.

\section{Onderzoek}

Om informatie te krijgen, deden wij onderzoek onder negentien praktijkondersteuners-ggz in de provincie Groningen, in het voorjaar van 2011. Dit onderzoek vond plaats vanuit het Universitair Medisch Centrum Groningen (UMCG), vakgroep huisartsgeneeskunde, in samenwerking met Regionale Ondersteunings Structuur ELANN (Eerste Lijns Advies Noord-Nederland). De praktijkondersteuners-ggz registreerden gedurende drie maanden hun patiëntencontacten.

Met de verzamelde gegevens wilden we antwoord geven op de volgende vragen. 1 Met welke patiënten en problemen krijgt de praktijkondersteuner- ggz te maken? 2 Welke werkzaamheden voert de praktijkondersteuner- ggz uit, en in welke mate? 3 In welke opzichten verschillen praktijkondersteuners- ggz in hun taakuitoefening? Maakt het uit of de praktijkondersteuner-ggz in dienst is van de huisartsenpraktijk, of niet?

\section{METHODE}

\section{Opzet}

Negentien praktijkondersteuners-ggz uit de provincie Groningen vulden gedurende drie maanden een registratieformulier in bij ieder contact van patiënten die zich nieuw aanmeldden. De registratie van contacten gebeurde in de periode maart-juni 2011.

Negen praktijkondersteuners-ggz waren in dienst van een huisartsenpraktijk, tien waren vanuit ggz-instellingen gedetacheerd in een huisartsenpraktijk.

Het aantal uren per week dat zij werkzaam waren, varieerde van 4 tot 32 uur per week; gemiddeld was het 15,2 uur per week. De meeste praktijkondersteuners- ggz waren opgeleid als sociaalpsychiatrisch verpleegkundige, 2 als B-verpleegkundige en 1 als maatschappelijk werker. Bij het eerste contact registreerde de praktijkondersteuner-ggz het geslacht en het geboortejaar van de patiënt. Verder legde hij vast door wie de patiënt was aangemeld en met welke problemen de patiënt was aangemeld. Zowel bij het eerste contact als bij ieder vervolgcontact legde hij de volgende gegevens vast:

- de duur van het consult;

- de ingeplande tijd voor het consult;

- de werkzaamheden die hebben plaatsgevonden tijdens het contact (probleemverheldering, testgebruik, behandeling, begeleiding, advisering, preventie); - Als behandeling gold: een gerichte interventie, gericht op klachtafname. Dit kon de praktijkondersteuner- ggz nader specificeren: problem solving therapy, motiverende gespreksvoering, psycho-educatie, cognitieve gedragstherapie, vijfgesprekkenmodel, begeleide zelfhulp, reattributie (een patiënt stimuleren om voor een lichamelijke klacht andere oorzaken te overwegen dan ziekte), of vaardighedentraining. Deze behandelvormen zijn in het algemeen goed toepasbaar binnen de eerste lijn in een beperkt aantal zittingen. ${ }^{4,5}$ - Behandeling en begeleiding golden als elkaar uitsluitende categorieën: behandeling was gedefinieerd als actieve interventie, begeleiding als meer passief. 
Verhaak, P., Zee, D. van der, Conradi, M., Bos, R. Praktijkondersteuner-ggz maakt verwachtingen waar. Tijdschrift voor Praktijkondersteuning: 2012, 7(2), 41-46

- Verwijzingen naar de eerste en/of tweede lijn;

- Vervolgafspraak (vervolg over ... dagen, verwijzing, contact beëindigd, ongespecificeerd vervolg).

\section{Analyse}

De praktijkondersteuners-ggz registreerden 950 contacten met 543 patiënten. Verrichtingen beschrijven we als percentage van het aantal contacten en als percentage van het aantal patiënten. Analyses van verwijzingen en de afronding van behandelingen hebben betrekking op het patiëntniveau.

\section{Respons}

Het aantal geregistreerde patiënten per praktijkondersteuner- ggz varieert van 2 tot 88 , het aantal geregistreerde contacten van 2 tot 152 . Voor verschillen tussen praktijkondersteuners-ggz die op patiënten betrekking hebben, beperken we ons tot 13 praktijkondersteuners-ggz die meer dan 10 patiënten hebben ingesloten. Voor verschillen die op contacten betrekking hebben, gebruiken we de gegevens van 16 praktijkondersteuners-ggz van wie we gegevens van meer dan 10 contacten hebben.

\section{RESULTATEN}

\section{De patiënten}

Van de patiënten die bij de praktijkondersteuner-ggz terechtkomen, is $70 \%$ vrouw. De leeftijd van de patiënten varieert van 5 tot 88 jaar, met de meerderheid tussen de 20 en 60 jaar. De gemiddelde leeftijd is 41 jaar; $5 \%$ is jonger dan 18 jaar. Bovenaan de top 5 van aangeboden problematiek staat stress of gespannenheid (bij $41 \%$ van de patiënten), als tweede relatieproblemen (32\%), op de derde plaats staat een depressief gevoel (24\%), op de vierde plaats angst of nervositeit (19\%), en op de vijfde plaats staan werkproblemen (16\%).

\section{Werkzaamheden}

Tabel 1 geeft de verschillende geregistreerde werkzaamheden van de poh-ggz weer. Bij de meeste contacten is sprake van probleemverheldering en ook van een of andere vorm van behandeling. De praktijkondersteuner- ggz geeft bij eenderde van de contacten adviezen. Preventie en testgebruik komen sporadisch voor. Bij eenvijfde van de contacten beperkt de praktijkondersteuner- ggz zich tot begeleiding of ondersteuning.

Bij meer dan 90\% van de patiënten vindt in een van de contacten probleemverheldering plaats, meestal in het eerste contact. De meerderheid van patiënten wordt behandeld en de helft krijgt advies.

Wanneer de praktijkondersteuner-ggz 'behandeling' heeft geregistreerd, specificeert hij ongeveer een kwart als 'problem solving therapy' en ongeveer een kwart als 'psycho-educatie'. Daarna volgen 'cognitieve gedragstherapie' en 'motiverende gespreksvoering'.

'Vijfgesprekkenmodel', 'begeleide zelfhulp' en 'vaardigheidstraining' vormen ieder zo'n 5\% van de behandelingen; 'reattributie' registreren de praktijkondersteunersggz het minst.

\section{[TABEL 1][FIGURE 1][FIGURE 2].}

In figuur 1 zien we hoe de 4 meest voorkomende werkzaamheden zijn verdeeld over de 16 praktijkondersteuners- ggz met meer dan 10 geregistreerde contacten. 
Verhaak, P., Zee, D. van der, Conradi, M., Bos, R. Praktijkondersteuner-ggz maakt verwachtingen waar. Tijdschrift voor Praktijkondersteuning: 2012, 7(2), 41-46

Variantie-analyse (een statistische techniek waarmee je vaststelt of er verschillen binnen en tussen groepen zijn) wees uit dat praktijkondersteuners-ggz significant van elkaar verschillen in de mate waarin ze elk van de 4 werkzaamheden uitvoeren $(\mathrm{F}=$ 4,83 voor probleemverheldering; 10,9 voor behandeling; 13,7 voor advisering en $60,7$ voor begeleiding; alle met df 15, $\mathrm{p}<0,0005)$. Praktijkondersteuners verschillen dus het minst van elkaar in de mate waarin ze aan probleemverheldering doen. Wat betreft begeleiding, behandeling en advisering zijn er onderling meer verschillen. Tussen praktijkondersteuners-ggz in dienst van een huisarts en in dienst van een ggzinstelling zijn er kleine verschillen in begeleiding en behandeling. Praktijkondersteuners-ggz in dienst van een huisarts registreren iets vaker 'behandeling' en praktijkondersteuners-ggz in dienst van de ggz iets vaker 'begeleiding'.

\section{Verwijzingen}

In totaal zijn er van de 543 patiënten 104 (19\%) verwezen naar een instantie binnen de eerste lijn en 68 (13\%) naar de specialistische ggz. In totaal zijn 163 (30\%) patiënten verwezen. Er komen 9 dubbeltellingen voor (zowel naar eerste lijn als naar de tweede lijn verwezen). De meeste verwijzingen binnen de eerste lijn (8\% van alle patiënten) betreffen een eerstelijnspsycholoog, in de tweede plaats komt het algemeen maatschappelijk werk (5\%), daarna de sociaalpsychiatrisch verpleegkundige in de eerste lijn (3\%: dit is in een enkel geval dezelfde als de praktijkondersteuner- ggz).

De meeste tweedelijnsverwijzingen (10\% van alle patiënten) betreffen de ambulante geestelijke gezondheidszorg. Ook bij het aantal patiënten dat praktijkondersteunersggz naar de eerste en naar de tweede lijn verwijzen, is er sprake van een significant verschil tussen praktijkondersteuners-ggz onderling $(\mathrm{F}=5,4$ respectievelijk 2,5; $\mathrm{df}=$ $15 ; \mathrm{p}<0,0001$ ): zie figuur 2. Er is geen verschil in aantallen verwijzingen tussen praktijkondersteuners-ggz in dienst van de huisarts en praktijkondersteuners-ggz in dienst van een ggz-instelling.

\section{Contactfrequentie}

Gemiddeld hebben patiënten met een afgeronde behandeling 1,8 contacten met een praktijkondersteuner- ggz. Ruim de helft heeft slechts 1 contact, ruim een kwart heeft 2 contacten, en een kleine 20\% heeft 3 tot 6 contacten. Deze aantallen zijn gebaseerd op de registraties door de praktijkondersteunersggz in een beperkte tijdspanne. Uit vragenlijsten die patiënten na 3 maanden retourneerden, blijkt dat bij deze groep $(n=$ 160) het gemiddelde aantal contacten 3,3 was, waarbij een kleine groep meer dan 6 contacten meldt.

In dit opzicht is er ook verschil tussen de praktijkondersteuners- ggz onderling ( $\mathrm{F}=$ $5,38$; $\mathrm{df}=12$, $\mathrm{p}<0,001)$. Het gemiddeld aantal contacten loopt uiteen van 1,1 tot 2,8. De praktijkondersteuner-ggz met het laagste gemiddelde aantal contacten heeft ook het hoogste verwijscijfer. Ruim tweederde van de contacten beëindigt de praktijkondersteuner-ggz met een vervolgafspraak. Veel cliënten met een vervolgafspraak ziet de praktijkondersteuner-ggz later niet meer terug. Dit kan betekenen dat een registratie van die vervolgafspraak door omstandigheden niet geregistreerd is, of dat de patiënt niet meer is komen opdagen. 
Verhaak, P., Zee, D. van der, Conradi, M., Bos, R. Praktijkondersteuner-ggz maakt verwachtingen waar. Tijdschrift voor Praktijkondersteuning: 2012, 7(2), 41-46

\section{BESCHOUWING}

De gemiddelde patiënt van de praktijkondersteuner ggz is een vrouw van middelbare leeftijd, met angst en depressie of psychosociale problemen in de relationele of werksfeer als meest voorkomende problemen. Deze problemen zijn grotendeels hetzelfde als bij patiënten met psychische problemen die bij de huisarts komen, en die de huisarts gewoonlijk verwijst naar een eerstelijnspsycholoog of andere eerstelijns ggz-instanties.

Wat wel verschilt: bij de praktijkondersteuner-ggz komen meer vrouwen dan bij de huisarts, meer dan in de totale groep mensen met psychische problemen in de huisartsenpraktijk, al dan niet verwezen naar eerstelijns-ggz. De patiënten van de praktijkondersteuner- ggz zijn gemiddeld jonger dan de patiënten met psychische problemen die alleen de huisarts ziet. ${ }^{6}$

\section{Taakomschrijving}

Praktijkondersteuners-ggz doen bijna bij iedere patiënt iets aan probleemverheldering. Bij tweederde van de patiënten treden ze behandelend op, bij een kwart beperken ze zich tot begeleiding. Van de patiënten die ze onder ogen krijgen, verwijzen zij 30\%: tweederde binnen de eerste lijn, eenderde naar de tweede lijn. De functie van de praktijkondersteuner-ggz in Groningen bestaat volgens deze resultaten uit probleemverheldering, met bij een deel van de patiënten kortdurende behandeling die zich beperkt tot een zitting of drie, en vervolgens snel doorverwijzen als het nodig is. Dat laatste geschiedt bij een derde van de patiënten. Deze functieinvulling komt in grote lijnen overeen met de in de inleiding geschetste taakomschrijving van de praktijkondersteuner-ggz. Een dienstverband bij de huisarts versus bij een ggz-instelling lijkt niet veel uit te maken. Praktijkondersteuners-ggz die in dienst zijn van een ggz-instelling, verwijzen niet vaker naar een eerste- of tweedelijns ggz-instelling, en zijn ook niet meer op behandeling georiënteerd dan hun collega's die in dienst zijn van een huisarts.

\section{Tussenstation}

Wat betreft het type patiënten en het probleemaanbod is er sprake van een sterke gelijkenis met de clientèle en het probleemaanbod bij de eerstelijnspsycholoog. ${ }^{7}$ De aanpak is echter duidelijk verschillend.

De eerstelijnspsycholoog is ingesteld op diagnostiek en behandeling en heeft een cliënt gemiddeld ongeveer zeven sessies onder zijn hoede. De praktijkondersteunerggz ziet de meeste patiënten maar een of twee keer. Voor eenderde van die patiënten is de praktijkondersteuner-ggz een tussenstation: ze worden daarna verwezen, bijvoorbeeld naar een eerstelijnspsycholoog.

Het is overigens niet gezegd dat voor de andere patiënten de psychische problemen dan verholpen zijn. Nogal wat patiënten lijken op een gegeven moment ook weg te blijven. Dit kan betekenen dat hun problemen over zijn, maar het kan ook betekenen dat men niet meer met de praktijkondersteuner- ggz verder wil.

\section{Beperkingen}

Uiteraard heeft dit registratieonderzoek zijn beperkingen.

In de eerste plaats moeten we afgaan op de gevallen die geregistreerd zijn, en we weten niet hoe vaak een praktijkondersteuner-ggz geen kans heeft gehad om iedere patiënt te registreren. We hebben hiernaar achteraf geïnformeerd, en de meeste praktijkondersteuners-ggz wijzen erop dat ze enkele patiënten (spoed tussendoor, 
Verhaak, P., Zee, D. van der, Conradi, M., Bos, R. Praktijkondersteuner-ggz maakt verwachtingen waar. Tijdschrift voor Praktijkondersteuning: 2012, 7(2), 41-46

vergeten toestemming te vragen) niet geregistreerd hebben. Bij een drietal praktijkondersteuners-ggz was het niet-geregistreerde aantal substantieel.

In de tweede plaats laten sommige begrippen die zij moeten registreren, enige ruimte voor interpretatie.

Zo zal de ene praktijkondersteuner-ggz een activiteit eerder als 'behandeling' registreren (een gerichte, actieve interventie), terwijl de ander het als 'begeleiding' zal interpreteren (de patiënt aanhoren en steunen, zonder gerichte actie). Dit interpretatieverschil blijkt uit het gegeven dat er praktijkondersteuners- ggz zijn die in alle contacten 'behandeling' registreerden, terwijl anderen dat maar zeer beperkt deden. Ondanks deze beperkingen hebben we een redelijk beeld gekregen van het patiëntenaanbod voor de praktijkondersteuner-ggz, de mate waarin deze verwijst dan wel de patiënt kort begeleidt, en de tijd die dit kost. Ten slotte kan vermeld worden dat deze gegevens verzameld zijn binnen de context van de provincie Groningen. In andere delen van Nederland kan zowel de mate waarin praktijkondersteuners-ggz ingezet zijn, als het aanbod van andere ggz-voorzieningen verschillen.

\section{Voorlopige uitkomsten}

Het is bemoedigend om te weten dat het niet uitmaakt of de praktijkondersteuner-ggz in dienst is van de huisartsvoorziening, of dat deze vanuit de tweedelijns- ggz werkt. Dat maakt het mogelijk om vanuit de tweede lijn menskracht in te zetten die vanuit een generalistisch perspectief werkt, niet onmiddellijk langdurig gaat behandelen, en niet meteen doorverwijst naar de tweedelijns-ggz.

Dit artikel doet slechts verslag van het eerste deel van dit onderzoek. De betrokken patiënten hebben bij de eerste behandeling een vragenlijst ingevuld over hun klachten en verwachtingen. Ruim 160 van hen hebben 3 maanden later op een tweede vragenlijst gereageerd, waarin ze de contacten met de praktijkondersteunerggz evalueerden en waarin ze opnieuw rapporteerden hoe het met hun klachten was. De laatste van deze nametingen zijn begin 2012 binnengekomen en hierover zullen wij in het voorjaar van 2012 rapporteren.

Op basis van deze eerste resultaten kunnen we concluderen dat de praktijkondersteuner-ggz een waardevolle aanvulling kan betekenen op de bestaande eerstelijnsggz, vooral om vragen te verhelderen en patiënten op efficiënte wijze naar een goede verdere behandeling te geleiden, dan wel om patiënten via een korte weg te helpen om met hun problemen om te gaan.

\section{LITERATUUR}

1 Ten Have JJIM. Praktijkondersteuning GGZ in de eerste lijn, Een eerste beschrijving van de functie praktijkondersteuning GGZ in de eerste lijn. Utrecht: Landelijke Vereniging Georganiseerde lijn, april 2007.

2 Leene I, Verberk F. Functieprofiel (startprofiel) Praktijk Ondersteuner Huisartsenzorg (POH) GGZ. Utrecht: Nederlandse Vereniging Maatschappelijk Werkers en Vereniging Verpleegkundigen en Verzorgenden, Nederland/Sociaal Psychiatrisch Verpleegkundigen, 2008.

3 Verhaak PFM, Van Beljouw IMJ, Have JJIM. De opmars van de poh-ggz. Tijdschr Praktijkonderst 2010;5:130-4.

4 Verhaak PFM, Zwaanswijk M, Ten Have JJIM. Psychologische interventies. Huisarts Wet 2011;54:23-8.

5 Gruijters P, Starmans R, Ten Have J, Blankenstein AH, redactie. U kunt het zelf:

Behandeling van psychische problemen in de huisartspraktijk. Den Haag: ZonMw, 2010.

6 Prins M, Verhaak P, Smit D, Verheij R. De positie van de eerstelijnspsycholoog in de eerstelijns-ggz. Huisarts Wet 2012;55:146-50. 
7 Verhaak PFM, Kamsma JPA, Van der Niet AG. Wie heeft baat bij eerstelijnspsychologische behandeling? GZ-psychologie 2011;3:16-23.

\section{TABELLEN EN FIGUREN.}

\section{Wat is bekend?}

In 2011 maakte naar schatting ongeveer 30\% van de huisartsen gebruik van de diensten van een praktijkondersteuner geestelijke gezondheidszorg (praktijkondersteuner-ggz).

- Naar eigen zeggen houden praktijkondersteuners-ggz zich vooral bezig met probleemverheldering, kortdurende behandeling en doorgeleiding van mensen met psychische klachten.

- Gegevens over de praktijkondersteuner-ggz waren uitsluitend gebaseerd op ondervraging van praktijkondersteuners-ggz.

\section{Wat is nieuw?}

- Dit is de eerste keer dat geregistreerde gegevens van praktijkondersteuners-ggz gepubliceerd worden.

- Deze beroepsgroep krijgt de alledaagse psychosociale problemen onder ogen: relatieproblemen, stress, angst en depressie. Ze zien patiënten slechts enige keren, en verwijzen eenderde van hen door.

- Doorverwijzing geschiedt het meest naar de eerstelijnspsycholoog en de ggz-instelling.

- Praktijkondersteuners-ggz in dienst van een ggz-instelling verwijzen niet vaker dan praktijkondersteuners-ggz in dienst van de huisarts.

- De praktijkondersteuner-ggz kan een waardevolle aanvulling betekenen op de bestaande eerstelijns geestelijke gezondheidszorg, in het bijzonder om vragen te verhelderen en patienten op een efficiënte wijze naar de goede plek van verdere behandeling te geleiden, dan wel de patiënt via een korte weg te helpen om met zijn problemen om te gaan. 
Tabel 1 Werkzaamheden praktijkondersteuner-ggz

\begin{tabular}{|c|c|c|}
\hline $\begin{array}{l}\text { Werkzaamheden* } \\
\text { praktijkonder- } \\
\text { steuner-ggz }\end{array}$ & $\begin{array}{l}\text { Aantal keer } \\
\text { geregistreerd }\end{array}$ & $\begin{array}{l}\text { Percentage van } \\
\text { de patiënten } \\
(\mathrm{n}=528)\end{array}$ \\
\hline Probleemverheldering & 545 & $91 \%$ \\
\hline Behandeling* & 545 & $62 \%$ \\
\hline Advisering & 336 & $49 \%$ \\
\hline $\begin{array}{l}\text { Begeleiding } \\
\text { (ondersteuning)* }\end{array}$ & 191 & $26 \%$ \\
\hline Preventieve ingreep & 86 & $13 \%$ \\
\hline Testgebruik & 48 & $9 \%$ \\
\hline Totaal & 1.751 & - \\
\hline
\end{tabular}

* Bij het invullen van het registratieformulier is het mogelijk om meerdere werkzaamheden tegelijk aan te kruisen (met uitzondering van begeleiding ('ondersteuning') en behandeling, die elkaar uitsluiten)

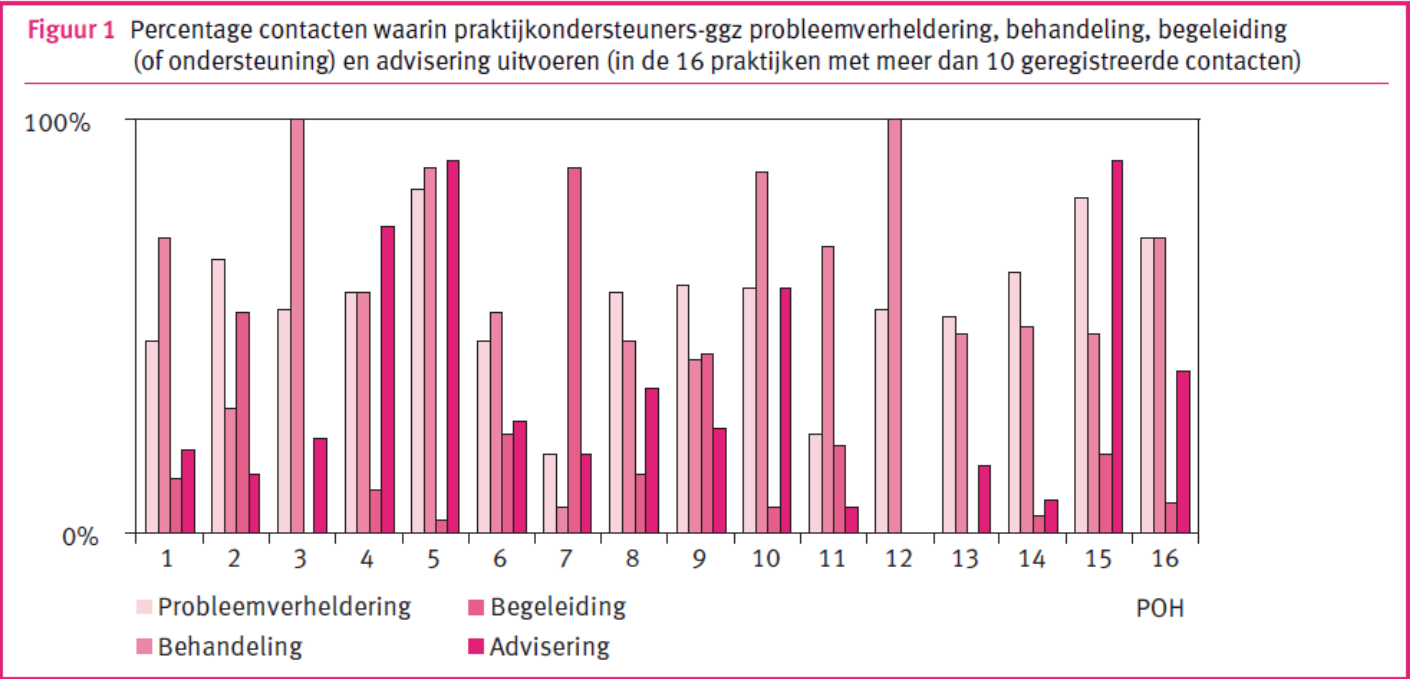


Verhaak, P., Zee, D. van der, Conradi, M., Bos, R. Praktijkondersteuner-ggz maakt verwachtingen waar. Tijdschrift voor Praktijkondersteuning: 2012, 7(2), 41-46
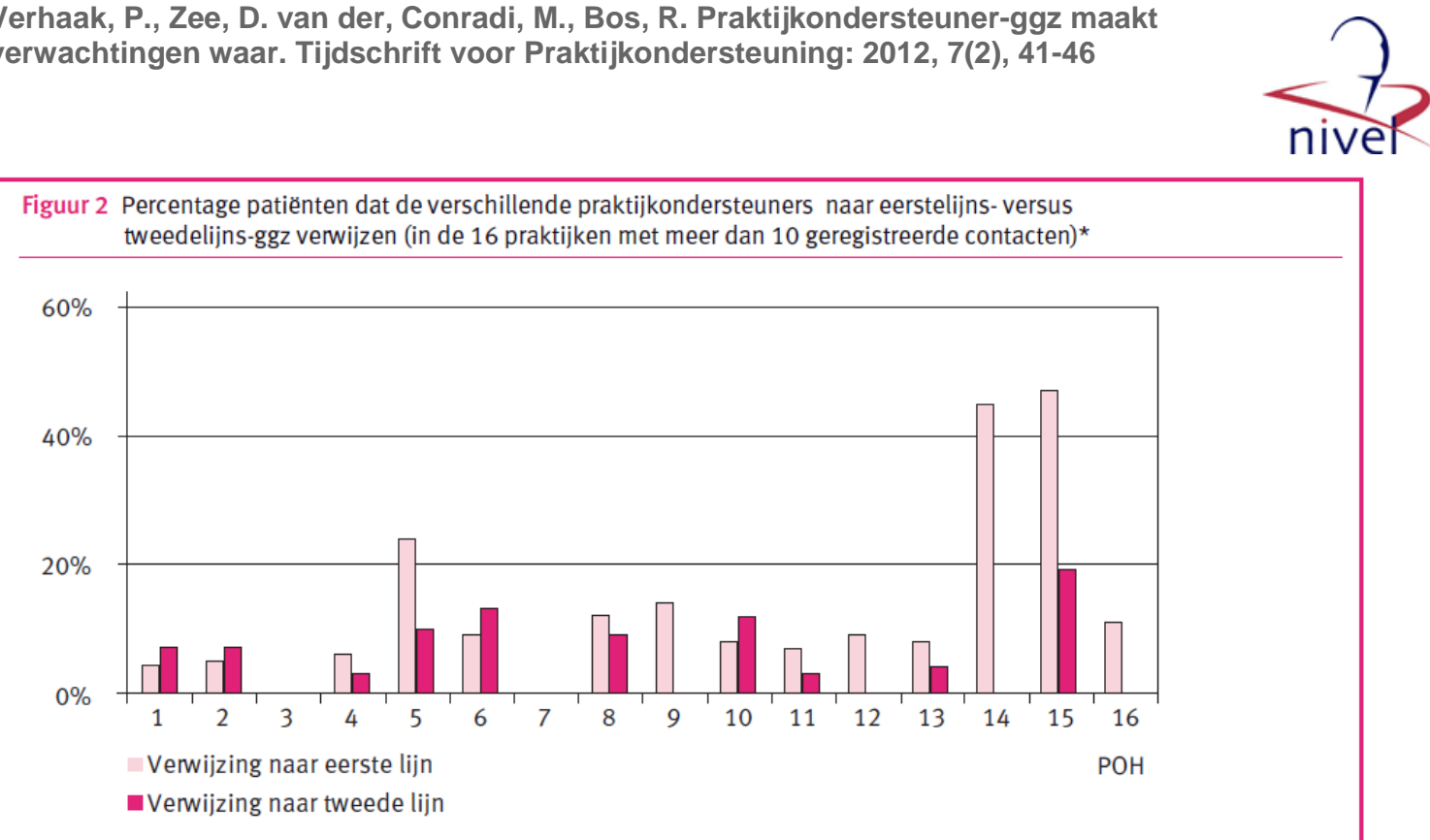

* Van de 22 praktijkondersteuners-ggz zijn er 3 niet gestart met het onderzoek; er hebben uiteindelijk 19 praktijkondersteuners-ggz meegedaan aan het onderzoek 